\title{
DEKLARASI BALFOUR : TRAGEDI BAGI BANGSA PALESTINA DALAM PUISI-PUISI ARAB TAHUN 1920-1948
}

\author{
Hindun \\ hindun@ugm.ac.id
}

Departemen Antarbudaya

Fakultas Ilmu Budaya UGM

\begin{abstract}
The arrival of Jews in Palestine since 1882 changed the order of life of the Palestinian people. Jews began to buy land from Palestinians with the aim of mastering all Palestinian land in the future. This mastery is carried out to realize the ideals of establishing a Jews country that has been proclaimed by The World Zionist Organization. The achievement of control of Palestinian land became apparent when the Ottoman Government in Palestine was defeated and turned into British hands. In 1917, Britain gave way to the Zionist Organization by signing the Balfour Declaration which gave permission to them to make Palestine a homeland. In three decades, the Zionist Organization succeeded in annexing Palestine and making it a Jewish state called Israel. The establishment of the state of Israel became a tragedy to the Palestinians. Arab poets have resisted since the signing of the Balfour Declaration until the tragedy of Israel's annexation of Palestine with their poems. Literary works, in the theory of adab almuqawamah, were written to arouse the spirit of resistance of a nation against colonialism. Arab poets through their poems warn of the adverse consequences of the Balfour Declaration for Palestine. Their poetry is also to arouse the fighting spirit of the Palestinian people against Israel.
\end{abstract}

Keywords : The Balfour Declaration, Britain, Palestine, Arab Poets, literary resistance

$$
\begin{aligned}
& \text { ملخص } \\
& \text { وصول اليهود في فلسطين منذ عام } 1882 \text { غيّر حياة الشعب الفلسطيني. بدأ اليهود في شراء الأراضي من من مأن } \\
& \text { الفلسطينيين بهدف إتقان كل الأراضي الفلسطينية في المستقبل. يتم هذا الإتقان لتحقيق المثل العليا لإقامة دولة } \\
& \text { خاصة لليهود التي أعلنتها المنظمة الصهيونية العالمية. أصبح تحقيق السيطرة على الأراضي الفلسطينية واضحا }
\end{aligned}
$$

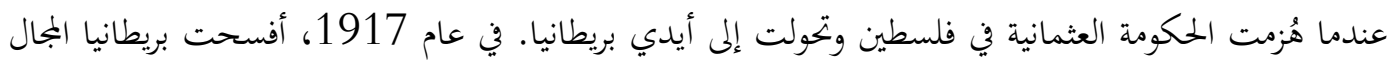

$$
\begin{aligned}
& \text { أمام المنظمة الصهيونية بتوقيعها على وعد بلفور الذي أعطى الإذن للمنظمة الصهيونية لجعل فلسطين وطنًا. } \\
& \text { خلال ثلاثة عقود ، نجحت المنظمة الصهيونية في ضم فلسطين وجعلها دولة يهودية تدعى إسرائيل. لقد أصبح }
\end{aligned}
$$

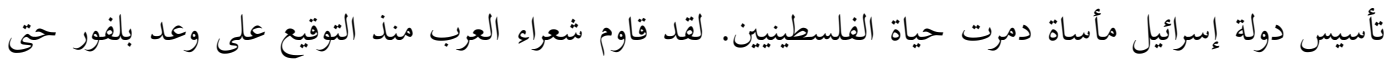

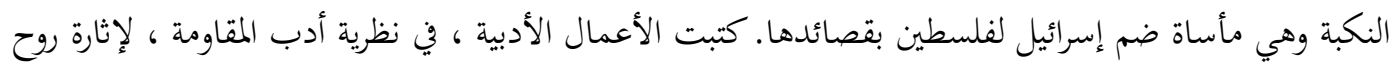

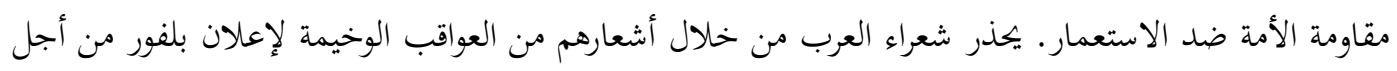

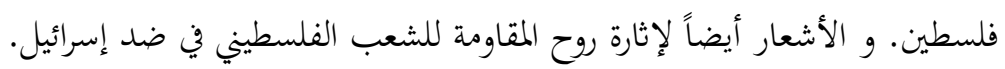

$$
\begin{aligned}
& \text { الكلمات المفتاحية : وعد بلفور، بريطانيا، فلسطين، شاعر العرب، أدب المقاومة }
\end{aligned}
$$




\section{Pendahuluan}

Kedatangan orang-orang Yahudi Rusia ke Palestina yang diatur oleh Organisasi Zionis Internasional sejak tahun 1882 sedikit demi sedikit mengubah kehidupan bangsa Palestina. Organisasi Zionis Internasional atau The World Zionist Organisation didirikan pada tahun 1897 oleh sejumlah orang-orang Yahudi Eropa di Basl, Switzerland dan diketuai oleh Theodor Herzl. Organisasi ini bertujuan untuk mendirikan sebuah negara khusus orang-orang Yahudi di tanah Palestina (Dimont, 1993:335; Shaleh, 2001:37). Perubahan yang disebabkan oleh para pendatang Yahudi itu disebabkan oleh bujukan yang mereka lakukan terhadap para pemilik tanah di Palestina agar menjual tanahnya sehingga lambat laun kepemilikan tanah Palestina oleh orangorang Yahudi semakin meluas. Kepemilikan atas tanah tersebut sebagai cikal bakal penguasaan tanah Palestina secara menyeluruh yang menjadi tujuan utama Zionis dalam pembentukan sebuah negara khusus Yahudi.

Organisasi Zionis mencari dukungan dari negara-negara Eropa untuk tujuannya tersebut. Dukungan terbesar diperoleh dari negara Britania Raya, padahal di negara ini tidak banyak orangorang Yahudi tinggal. Akan tetapi, di antara orang Yahudi di Inggris, Chaim Weizmann, seorang ahli kimia yang menemukan revolusi metode dalam memproduksi bahan kimia berdaya ledak tinggi yang digunakan Inggris dalam perang. Dimont (1993:338) menyebutkan bahwa "dalam Perang Besar (Great War), Chaim Weismann dipanggil memasuki British War Office untuk menemukan sebuah cara untuk memproduksi kordit sintetis, sebuah bahan peledak bagi perang Inggris". Atas jasa besar inilah Weizmann meminta Inggris agar memberikan bantuan kepada Organisasi Zionis untuk mewujudkan cita-cita mereka membentuk suatu negara khusus Yahudi.

Deklarasi Balfour adalah surat tertanggal 2 November 1917 dari Menteri Luar Negeri Britania Raya, Arthur James
Balfour, kepada Lord Rothschild, pemimpin komunis Yahudi Inggris, untuk dikirim kepada Federasi Zionis. Surat ini kemudian disebut Deklarasi Balfour 1917 atau Deklarasi Balfour I (Tucker, 2008:191). Surat ini menyatakan bahwa pemerintah Inggris mendukung rencanarencana Zionis untuk mendirikan tanah air Yahudi di Palestina. Deklarasi Balfour inilah yang menentukan bahwa organisasi Zionis dapat mendirikan sebuah negara khusus orang-orang Yahudi di wilayah Palestina. Meskipun dalam Deklarasi tersebut dikatakan bahwa tidak boleh melakukan hal-hal yang merugikan kehidupan bangsa Palestina, tetapi itu hanya sebagai tipu muslihat karena yang terjadi Israel boleh melakukan apa saja tanpa ada batasan.

Perpindahan orang-orang Yahudi dan pendudukan Israel di Palestina menyebabkan perubahan besar-besaran dalam kehidupan bangsa Palestina. Hal itu mengusik para penyair dari berbagai kawasan Arab untuk menulis puisi yang menggugah kesadaran orang-orang Palestina. Para penyair mengingatkan orang-orang Palestina dan bangsa Arab secara luas akan bahaya zionisme dan mengingatkan akibat buruk yang menimpa bangsa Palestina akibat penjajahan Israel yang awal mulanya berasal dari penandatanganan Deklarasi Balfour.

Penelitian tentang puisi ini telah dilakukan oleh Abdurrahman Yāgī dari Universitas Yordania, yang berjudul Fi alAdabi al-Falasținiyyi al-Hadìs: Qabla anNakbah wa Ba'dahā yang membicarakan sastra Arab-Palestina, baik prosa maupun puisi, yang lahir pada tahun 1908 sampai tahun 1970-an. Periodisasi terbagi atas masa sebelum "Bencana (an-Nakbah) 1948", sesudahnya dalam waktu yang dekat, dan masa sesudah Palestina dalam keadaan terjajah sampai tahun 70-an. Karya sastra yang menjadi objek materialnya adalah karya-karya yang mengandung perlawanan terhadap pendudukan Israel. Penelitian selanjutnya dilakukan Qusay al-Husain dengan 
memanfaatkan teori sastra perlawanan. Penelitiannya berjudul al-Mautu wa alHayatu fì Syi'ri al-Muqāwamah. Ia berpendapat bahwa puisi yang termasuk dalam kategori puisi perlawanan adalah puisi-puisi Palestina karena puisi itu berbicara tentang peristiwa-peristiwa yang benar-benar terjadi di Palestina.

Pemaparan hasil-hasil penelitian terdahulu, baik dari segi objek material maupun objek formal, dapat mendudukkan penelitian yang dilakukan ini, yaitu Deklarasi Balfour yang menyebabkan terjadinya tragedi bangsa Palestina yang terdapat dalam puisi-puisi para penyair Arab tahun 1920-1948. Dipilih tahun 1920 karena puisi-puisi yang lahir tahun ini berkaitan dengan diumumkannya Deklarasi Balfour tahun 1917. Oleh karena itu, permasalahan dalam penelitian ini adalah bagaimana perlawanan para penyair Arab terhadap Deklarasi Balfour yang menyebabkan tragedi aneksasi Israel atas bangsa Palestina?

\section{Teori dan Metode}

Teori yang dimanfaatkan dalam tulisan ini adalah teori adab almuqāwamah. Secara etimologi muqāwamah adalah bentuk kata benda yang berasal dari akar kata "qāma" 'berdiri, bangkit, berhenti, mulai mengerjakan' (Munawwir, 1997:1172), lalu berubah polanya menjadi qāwama yang berarti 'berhenti, menentang dan melawan terhadap sesuatu' (Munawwir, 1977:1173) sehingga kata muqāwamah berarti 'hal berhenti, melawan dan menentang terhadap sesuatu'. Sementara itu, menurut Al-Ayyūbiy (dalam alHusain, tt:11) qāwama mengandung arti al-wuqūfu al-misili 'hal berhenti', alwuqūfu bi al-muqābili 'hal berhenti berhadapan', șamūdun 'ketetapan', dan sabātun 'keteguhan'. Dengan kandungan beberapa arti tersebut, kata muqāwamah yang berasal dari kata qāwama mengandung arti "hal ketetapan dan keteguhan dalam melawan dan menentang terhadap sesuatu dengan penolakan dan pemberontakan".

Secara terminologi, adab almuqāwamah dalam sastra Arab pertamatama dikemukakan oleh Mahmūd Darwīsy, yaitu karya sastra yang mengungkapkan penolakan yang mendalam terhadap sesuatu hal yang terjadi dengan meyakini bahwa perlawanannya akan berhasil (dalam alHusain, tt:12). Sementara itu, Kanafaniy menjelaskan bahwa "adab al-muqāwamah adalah sastra yang membangkitkan semangat perjuangan melawan penjajahan" (via al-Ustah, tt:3). AlAyyūbiy (dalam al-Husain, tt:11) sebagai penerus gagasan adab al-muqāwamah menjelaskan pengertiannya sebagai berikut.

'Sastra perlawanan adalah
hasil pemikiran yang
membicarakan penolakan dan
penentangan pada masa
pendudukan dan penjajahan
dan digunakan $r$ untuk
mengarahkan ran
membangkitkan masyarakat
agar menjaga keberadaannya
dalam hal keyakinan,
keilmuan, warisan budaya,
dan masalah-masalah sosial
lainnya'.

Al-Ayyūbi melanjutkan definisi di atas dengan penjelasan bahwa adab almuqūwamah adalah konsep perjuangan melawan penjajahan dengan menggunakan senjata berupa kata-kata yang dianggap lebih unggul dibandingkan meriam atau senjata lainnya. Sastra perlawanan dalam sastra Arab merupakan sebuah alat untuk menggerakkan emosi jiwa bangsa Arab agar timbul pemikiran, rasa keberanian, rasa penuntutan balas, dan rasa pembelaan sehingga suatu pendudukan dan penjajahan itu harus dihentikan (Al-Husainiy, 2006:29). Dengan demikian, sastra perlawanan adalah salah satu alat untuk membantu perjuangan suatu bangsa untuk memperoleh kemerdekaannya. Sastra tersebut ditulis oleh para sastrawan 
Palestina khususnya dan Arab umumnya (al-Ayyūbiy, tt:11). Karena istilah sastra perlawanan dalam sastra Arab ini lahir setelah peristiwa pendudukan Israel atas Palestina pada Mei 1948 dan Juni 1967, maka sastra perlawanan dapat dikatakan identik dengan sastra perlawanan Palestina terhadap Israel (al-Ayyūbiy, $\mathrm{tt}: 11)$.

Secara metodologis dan prosedural, untuk menganalisis perlawanan ArabPalestina terhadap Israel yang terdapat di dalam puisi-puisi Arab dilakukan dengan metode al-ijtimā'iy at-tārīkhiy 'sosiohistoris', yaitu "menghubungkan karya sastra dengan peristiwa sejarah, politik, dan kondisi masyarakat" (as-Suyūfiy, 2008:167). Dalam penelitian ini, peristiwa yang disebutkan dalam puisi dihubungkan dengan peristiwa yang terjadi di Palestina karena sastra pada setiap bangsa merupakan gambaran kehidupan yang dapat dipercaya dan rekaman yang lengkap terhadap peristiwa-peristiwa yang telah terjadi. Teknik analisis kontekstual dalam penelitian ini adalah dengan penelusuran sumber-sumber primer dan sumber-sumber sekunder yang berkaitan dengan sosio-historis bangsa Palestina. Dari analisis tekstual dan kontekstual ini selanjutnya dapat diungkap perlawanan bangsa Arab-Palestina terhadap penjajahan Israel yang disebabkan oleh penandatanganan Deklarasi Balfour.

\section{Pembahasan}

Antara tahun 1920-1948 telah lahir puisi-puisi karya para penyair Arab yang membicarakan dan mempertanyakan Deklarasi Balfour. Para penyair Arab yang puisinya membicarakan pandangannya atas Deklarasi Balfour adalah Salim Hasan al-Ya`qubi, Abdurrahim Mahmud, Ibrahim adDabbag, Nasr Sam'an, dan Zaki Konsul.

\section{Deklarasi Balfour dalam Pandangan Para Penyair Arab}

Puisi yang pertama-tama memperingatkan bangsa Palestina akan dampak yang diakibatkan oleh Deklarasi
Balfour adalah puisi yang disampaikan oleh Salim Hasan al-Ya'qubiy yang lahir di Lida Palestina pada tahun 1880 dan meninggal pada tahun 1946 (Syarāb, 2006:176). Ia adalah salah satu penyair yang menentang Deklarasi Balfour sebelum deklarasi ini diumumkan. Deklarasi Balfour adalah deklarasi yang memberi ijin kepada Israel untuk membentuk negara khusus orang-orang Yahudi. Puisinya memperingatkan bangsa Palestina akan bahaya yang mengancamnya akibat penjajahan Inggris dan Deklarasi Balfournya itu. Ia telah meninggal dua tahun sebelum Zionis mengumumkan berdirinya negara Israel di bumi Palestina, ia telah mengatakan penderitaan yang akan dialami Palestina apabila Inggris mengumumkan suatu deklarasi yang nantinya disebut Deklarasi Balfour. Ia mengatakan:

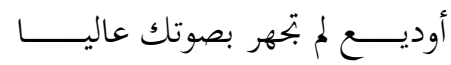

$$
\begin{aligned}
& \text { و الدار حتى اليــوم في أغلالـهـا }
\end{aligned}
$$

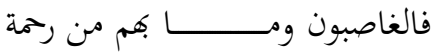

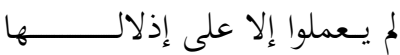

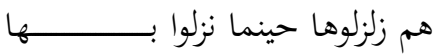

$$
\begin{aligned}
& \text { و كفى الخطوب تزيد في زلزالـها } \\
& \text { فلم السكوت و أنت بالأدب الذي أنو نيل }
\end{aligned}
$$

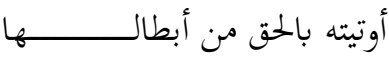

(Syarāb, 2006:176-177)

'Aku menitipkan, ia (Palestina) yang tidak jelas dengan suaramu yang lantang, sedangkan rumah (Palestina) hingga sekarang dalam belenggunya (Inggris)

Para pemakai tanpa izin itu sama sekali tak punya belas kasihan. Mereka berbuat hanya atas dasar kemauan mereka

Mereka menggoncangnya (Palestina) ketika mereka tinggal di dalamnya dan segala pembicaraan semakin menambah goncangannya Mengapa diam? Sedangkan engkau dapat mengemukakan kebenaran dengan sastra dari para tokohnya' 
Puisi ini membicarakan adanya rencana Inggris terhadap Palestina. Dikatakan bahwa status Palestina "tidak jelas" setelah pembagian batas negaranegara Arab berdasarkan negosiasi yang dilakukan oleh Inggris bersama Syarif Husain bin Ali, Emir Hijaz pada tahun 1915-1916 yang berisi dorongan Inggris agar Syarif Husain mendeklarasikan revolusi Arab terhadap pemerintahan Ottoman (Shaleh, 2002:40). Tujuan Inggris bukanlah untuk kemerdekaan Arab atas Ottoman, melainkan untuk mengamankan wilayah jajahannya di Syam (wilayah yang sekarang meliputi Palestina, Libanon, Yordania, dan Syria) dan kepentingannya atas Terusan Suez untuk mendukung persoalan perekonomian. Kenyataannya hingga puisi ini ditulis dikatakan "Palestina dalam belenggunya", Palestina tidak akan merdeka dari Ottoman seperti janji Inggris, melainkan justru ada dalam cengkeraman Inggris.

Palestina telah kedatangan orangorang yang disebut 'para pemakai tanpa izin'. Mereka adalah orang-orang Yahudi yang datang secara massal dari wilayah Eropa, terutama Rusia, yang diatur oleh Organisasi Zionis Internasional sehingga kedatangannya di Palestina telah terencana dengan rapi. Dikatakan bahwa dua kelompok dari sebuah komite Rumania di Galatz telah berlayar dan tiba di The Land pada awal tahun 1882 (Parker, 2002:332). The Land yang dimaksud adalah tanah Palestina. Setelah di Palestina, mereka mendapat biaya dari organisasi untuk membeli tanah-tanah pertanian milik orang Palestina sehingga dalam waktu pendek orang-orang Yahudi telah dapat menguasai tanah secara meluas. Orang-orang Yahudi ini disebut al-gasibun 'yang memakai tanpa izin' karena selain menguasai tanah, mereka juga membuat aturan-aturan sendiri tanpa memperdulikan bangsa Palestina sebagai bangsa yang memiliki tanah Palestina itu.

Selanjutnya adalah Abdu ar-Rahim Mahmud (1913-1948), seorang penyair
Palestina yang ikut berjuang menyelamatkan tanah airnya dengan menjadi tentara yang ikut bertempur dalam beberapa pergolakan (Syarāb, 2006:239). Ketika Deklarasi Balfour diputuskan oleh Inggris untuk dilaksanakan, ia mengatakannya dalam puisinya berikut.

$$
\begin{aligned}
& \text { بلفور، ما بلفور، ماذا وعده؟ } \\
& \text { لو لم تكن أفعالنــا الإبرام } \\
& \text { إنا بأيدينا جرحنا قلبـــــــــــا } \\
& \text { وبنا إلينا جــاءت الآلام }
\end{aligned}
$$

(Syarāb, 2006:9)

'Balfour, apa Balfour itu? Apa perjanjiannya? Seandainya tidak karena perbuatan gigih kita (menolak persetujuan perjanjian itu), hati kita terluka oleh tangan kita sendiri dan kepedihan itu datang karena kita sendiri'

Puisi ini mempertanyakan apa itu Deklarasi Balfour dan apa isi perjanjiannya? Pertanyaan ini bukanlah sebuah pertanyaan biasa, tetapi pertanyaan retoris, yaitu pertanyaan yang membutuhkan jawaban berupa sikap pihak Inggris yang mengeluarkan Deklarasi Balfour itu. Mengapa Inggris yang saat itu menjajah Palestina dapat memutuskan mengubah Palestina menjadi tanah atau negara khusus bagi orang-orang Yahudi. Puisi ini juga mempertanyakan isi perjanjian itu sehingga dapat menyebabkan negeri Palestina menjadi negara Yahudi?.

Deklarasi Balfour adalah mulainya penderitaan bangsa Palestina. Hal itu dapat dilihat dari ungkapan 'kalau bukan perbuatan gigih kita' yang menunjukkan bahwa bangsa Palestina dan bangsa Arab lainnya, terutama para pemimpinnya, harus berusaha keras menolak dilaksanakannya Deklarasi Balfour ini. Apabila penolakan tidak dilakukan dengan sungguh-sunguh, maka siapa lagi yang dapat mempertahankan eksistensi tanah air. Bahkan, dikatakan 
bahwa 'kita melukai hati kita dengan tangan kita' dan 'kepedihan itu datang oleh kelakuan kita sendiri' yang dengan ungkapan apabila Deklarasi Balfour itu terlaksana, maka penderitaan segera menimpa bangsa Palestina dan Palestina tidak akan beralih rupa menjadi Israel.

Deklarasi Balfour adalah sebutan untuk sebuah kebijakan yang dikeluarkan oleh pemerintah Inggris yang dikirimkan oleh Sekretaris Luar Negreri Inggris, yaitu Arthur James bekerjasama dengan Perdana Menteri David Lloyd Goerge, kepada pemimpin Zionis di Inggris saat itu, yaitu Lord Rothschild. Deklarasi Balfour dikirimkan pada 2 November 1917 itu berbentuk sebuah surat yang isinya sebagai berikut.

Dear Lord Rothschild:

I have much pleasure in conveying to you on behalf of His Majesty's Goverment the following declaration of our sympathy with Jewish Zionist aspirations which has been submitted to, and approved by, the Cabinet. 'His Majesty's Government view with favour the establishment in Palestine of a National Home for the Jewish poeple, and will use their best endeavour to facilitate the achievement of this object, it being clearly understood that nothing shall be done which may prejudice the civil and religious rights of existing non-Jewish communities in Plestine, or the rights and political status enjoyed by Jews in any other country. I should be gratiful if you would bring this declaration to the knowledge of the Zionist Federation. Your sincerely,

(Arthur James Balfour)

(Hiro, 1996:47-48)

Isi yang paling penting dari surat di atas adalah pemberian ijin secara resmi dari Pemerintah Inggris kepada organisasi Zionis bahwa mereka dapat mendirikan $a$ national home bagi orang-orang Yahudi di Palestina. Penggunaan istilah a national home bukan homeland atau negara merupakan sebuah kesengajaan yang dilakukan Inggris untuk mengaburkan pendudukan yang segera dilakukan atas Palestina. Masalahnya, Palestina adalah sebuah tanah air bagi suatu bangsa, lalu bagaimana Inggris dapat menentukan begitu saja pendirian suatu negara di negara milik bangsa lain.

Inggris memberi kesan kepada bangsa Palestina bahwa Deklarasi Balfour itu bukan masalah penguasaan Inggris atas Palestina. Kesan itu diberikan dengan ketidakhadiran Inggris di Palestina setelah Deklarasi Balfour diumumkan. Goldsmith mengatakan "At the time of issuing, Palestine was not under British control" (Bazian, tanpa tahun). Setelah sebulan kemudian barulah Inggris masuk Palestina dan itupun masih memberi kesan bahwa Inggris hanya membantu mengatur saja tidak mengusai Palestina. Padahal yang terjadi Inggris menyediakan jalan mulus bagi Israel untuk menguasai tanah Palestina.

Sejak deklarasi Balfour dilihat sebagai Magna Charta politik Zionisme, hal ini menandakan bahwa Inggris menginginkan Palestina menjadi Negara Yahudi. Pemerintah Inggris hanya berjanji untuk menciptakan Negara Yahudi di Palestina. Menurut pemerintah Inggris, hal ini tidak melanggar hak sipil dan kehidupan beragama di Palestina. Baik Inggris dan gerakan Zionis, keduanya harus menemukan cara untuk meyakinkan penduduk Palestina untuk menjamin hakhak mereka sebagaimana yang dijelaskan dalam kutipan berikut.

" The British government promised only to work for the creation of a Jewish national home in Palestine. Moreover, it pledged not to harm the civil and religious rights of Palestine's “existing non-Jewish communities"-namely, the 93 percent of its inhabitants, Muslim and Christian, who spoke Arabic and did not want to be separated from other Arabs as the second class citizens within a Jewish 
national home (Goldschmidt, 2010:245)

Meskipun Inggris telah berjanji seperti itu, kenyataannya dalam Deklarasi Balfour itu terkandung maksud yang membahayakan eksistensi bangsa Palestina karena tujuan yang sesungguhnya adalah penghapusan bangsa Palestina yang dilakukan dengan cara memusnahkan bangsa Palestina dengan berbagai cara pembunuhan.

Deklarasi Balfour tidak hanya lahir dari tangan Inggris, melainkan melibatkan negara lain, yaitu Prancis, Jerman, Rusia, dan bahkan Amerika. Deklarasi Balfour dengan cepat menimbulkan berbagai permasalahan di Palestina. Pertama-tama adalah kedatangan orang-orang Yahudi ke Palestina secara terencana. Menanggapi permasalahan akibat Deklarasi Balfour ini Ibrahim ad-Dabbag, seorang penyair Palestina kelahiran Yafa pada tahun 1880 (Syarāb, 2006:32), menulis puisi ketika Deklarasi Balfour mulai menunjukkan dampak buruk pada negerinya, ia mengatakan:

$$
\begin{aligned}
& \text { ما وعد بلفور من أمر السماء و لا } \\
& \text { في الجذب من أرضنا زرعٌ لمحتطب } \\
& \text { ما حكمه بعد أحكام السماء ولا } \\
& \text { يرضى به بعد حكم الله غير غبي }
\end{aligned}
$$

(Syarāb, 2006:9)

'Deklarasi Balfour itu bukanlah perintah langit dan tidak ada tanaman bagi pencari kayu yang menarik di bumi kita

'Apa hukumnya setelah hukum langit dan tidaklah yang menyetujui hukum ini setelah hukum Allah kecuali orang yang sangat bodoh'

Puisi ini mengatakan bahwa Deklarasi Balfour bukanlah 'perintah langit' yang maksudnya adalah hukum Tuhan yang wajib dilaksanakan. Deklarasi Balfour berisi janji-janji Inggris yang memberikan tanah Palestina kepada pihak yang tidak berhak memilikinya, yaitu Zionis. Ini adalah keputusan yang tidak dapat diterima oleh semua orang yang berakal sehat. Memberikan tanah air yang dimiliki suatu bangsa kepada pihak penjajah adalah kejahatan di atas kejahatan. Inilah yang dimaksud oleh ungkapan dalam puisi ini bahwa Deklarasi Balfour melebihi hukum Tuhan sehingga dikatakan 'Apa hukumnya setelah hukum langit?'. Ad-Dabbag bahkan mengatakan bahwa pihak yang menyetujui pelaksanaan Deklarasi ini hanyalah orang yang gabiyyu 'yang sangat bodoh' yang secara wajar logika pikirnya tidak dapat diterima.

Tidak hanya para penyair Palestina saja yang membicarakan bahaya Deklarasi Balfour. Para penyair mahjar, yaitu para penyair Arab yang berpindah domisili di Amerika, ikut merasa prihatin dengan kehancuran Palestina akibat Deklarasi Balfour. Dia adalah Nasr Sam'an yang mengatakan,

$$
\begin{aligned}
& \text { أفي مهد الســالام وغى تلظى } \\
& \text { و تصيــغ بالدم القــــاني الترابا } \\
& \text { سيلقى الانكليز من الزوايــــا } \\
& \text { قوافل أخطأوا فيـــا الحســــابا }
\end{aligned}
$$

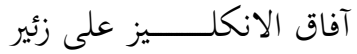

$$
\begin{aligned}
& \text { يهز وهـــــــاد لندن و الهضابـا } \\
& \text { و إن اللورد مثل الغول معنى } \\
& \text { و من يستنصف الغيلان خابـا }
\end{aligned}
$$

(Haddād, 1982:205)

'Apakah pada masa damai itu ada kegaduhan dan tanah tersepuh darah merah tua

Inggris akan melemparkan gembok-gembok dari berbagai penjuru yang sebabkan mereka salah perhitungan

Cakrawala Inggris adalah geraman dan raungan yang menggoyang dataran rendah dan dataran tinggi London

Sesungguhnya Lord itu seperti hantu kebinasaan dan barangsiapa yang seperti hantu kebinasaan ia rugi' 
Puisi Sam`an menggambarkan keadaan Palestina yang dikatakan oleh Inggris akan menjadi negara merdeka setelah terlepas dari kekuasaan Ottoman, sedangkan keadaannya sebenarnya "tersepuh darah merah" karena terjadi pergolakan-pergolakan yang menimbulkan banyak korban. Pergolakan terjadi sebagai penolakan terhadap kekuasaan Zionis dan orang-orang Yahudi yang semakin membesar di Palestina. Antara tahun 1918-1933 telah terjadi empat kali pergolakan yang disebut Revolusi Musa an-Nabi (1920), Revolusi Yafa (1921), dan Revolusi Buraq (1929) dan selanjutnya tahun 1933 terjadi demonstrasi besar di al-Quds dan Yafa (Shaleh, 2001:49-60).

Pergolakan-pergolakan yang dilakukan bangsa Palestina tidak membuahkan hasil karena Inggris terus mendukung Zionis memperkuat eksistensinya di Palestina. Pernyataan "Inggris melempar gembok dari segala penjuru" menunjukkan bahwa Inggris membangun perlindungan bagi Zionis dari segala arah dan menjauhkan bangsa Palestina dari tanah airnya karena pintu yang digembok bermaksud melindungi orang yang ada di dalam dan menghalangi orang luar untuk masuk. Keadaan Palestina ini disebabkan oleh "raungan Inggris" yang wujudnya adalah Deklarasi Balfour yan gaungnya mengguncang seluruh dunia Arab, khususnya Palestina. Deklarasi diprakarsai oleh "Lord", yaitu Lord Arthur James Balfour sehingga Lord dianggap sebagai "hantu kebinasaan" karena deklarasi itu dengan cepat membawa dampak buruk bagi bangsa Palestina sebelum bangsa Palestina sadar dengan yang telah terjadi.

Puisi Nasr Sam'an juga mengingatkan kepada orang-orang Timur agar selalu sadar bahwa Barat itu lalim. Contohnya adalah Balfour yang menyebabkan orang Palestina sengsara karena perjanjian yang dibuatnya. Nasr mengatakan:

$$
\text { يا شرق لا تسنس بغرب ظالم }
$$

$$
\begin{aligned}
& \text { فنــقول عـل فؤاده إن يرحما } \\
& \text { بلفور و الأسطول فوق لسانه } \\
& \text { يمشي فكيف يحل وعدا مبرما }
\end{aligned}
$$

(Haddād, 1982:206)

'Wahai Timur, jangan lupakan Barat yang lalim sehingga kita berkata sesungguhnya hatinya baik jika ia penyayang

Balfour dan armadanya di atas lisannya itu berjalan, maka bagaimana ia melepaskan janji yang tidak dapat dielakkan'

Puisi di atas mengingatkan para pemimpin Arab agar jangan sampai terlena pada rencana-rencana yang dibuat oleh Barat. Ungkapan "sehingga kita berkata sesungguhnya hatinya baik jika ia penyayang" menunjukkan bahwa pihak Arab sering terkecoh atas janji-janji Barat yang terlihat menguntungkan Arab, tetapi kenyataannya merugikan. Salah satu kelicikan Barat adalah keberhasilan Inggris mendapat pengakuan internasional dengan "Resolusi PBB tanggal 24 Juli 1922, yaitu resolusi yang melegalkan kekuasaan di Palestina dan bertanggung jawab memberikan jaminan hak-hak sipil dan agama bangsa Palestina" (Shaleh, 2002:46). Yang terjadi justru sebaliknya, bait kedua menjelaskan bahwa Balfour justru memantapkan rencananya dan rencana itu pasti akan dilaksanakan, yaitu mendirikan negara Yahudi di Palestina.

Puisi lain yang mengemukakan pendapatnya tentang peran Inggris melalui peran James Balfour dan Winston Churchill sebagai pihak yang melahirkan tragedi Palestina adalah Zaki Qansul. Puisinya sebagai berikut.

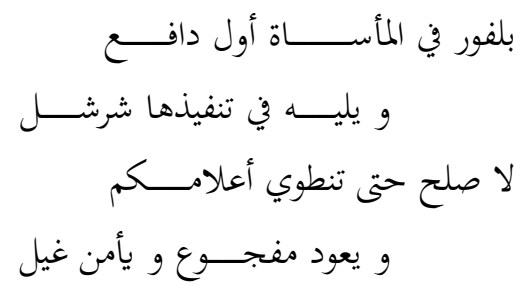

(Haddād, 1982:227) 
'Balfour dalam sebuah tragedi ini adalah pendorong utama, lalu dilaksanakan oleh Churchill

Tak ada perdamaian sampai kau lipat benderamu dan orang-orang tersakiti itu kembali, sedangkan tenteramlah huruhara'

Penetapan Deklarasi Balfour benarbenar awal suatu tragedi panjang bagi bangsa Palestina. Bangsa Palestina tidak mampu menolak akibat dari penetapan itu karena kuatnya dukungan negara-negara Eropa dan Amerika atas terlaksananya pendirian negara Yahudi di Palestina yang dalam puisi di atas dikatakan dengan ungkapan 'dilaksanakan oleh Churchill'. Setelah penetapan Deklarasi pada masa Balfour, Perdana Menteri Inggris berikutnya, Winston Churchill, yang menjabat pada tahun 1945-1955 terus mengawal bahwa negara Yahudi betulbetul berdiri dengan stabil di Palestina. Bagi bangsa Palestina, kedamaian adalah apabila pihak Israel dan Zionis 'telah melipat bendera' mereka. Artinya Zionis telah keluar dari bumi Palestina dan orang Palestina yang terusir dapat kembali ke tanah air mereka.

Selanjutnya adalah puisi Qaisar Khūriyyu (1893-1977), seorang penyair mahjar asal Libanon. Ia mengatakan,

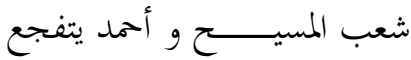

$$
\begin{aligned}
& \text { فالقدس جــازعة و مـكة تدمع } \\
& \text { يا ويح (ســــان ريمو) فإن قرارها } \\
& \text { ضجت لرنسته الجهات الأربعاء } \\
& \text { داسوا البلاد و قطعوا أوصــــــالها }
\end{aligned}
$$

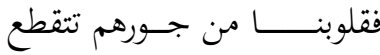

$$
\begin{aligned}
& \text { مــــــا راقهم شعب بريء مخلص }
\end{aligned}
$$

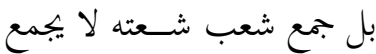

$$
\begin{aligned}
& \text { قطعوا العهود على ابتلاع حقوقنا }
\end{aligned}
$$

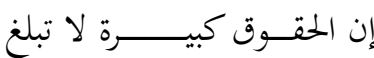

$$
\begin{aligned}
& \text { قطعوا العهود على البلاد وما دروا }
\end{aligned}
$$

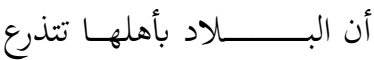

$$
\begin{aligned}
& \text { أنظارهم : فالعرب حول بـادهم } \\
& \text { ســور أعز من العقاب و أمنع }
\end{aligned}
$$

(Syarab, 2006:325)

'Bangsa al-Masih (Nabi Isa) dan Ahmad (Muhammad) tersakiti secara tiba-tiba, sedangkan Makkah berlinang air mata

Ah, celakalah San Remo. Keputusannya itu mengguncang empat penjuru Karena gemanya, mereka menginjak suatu negeri dan memotong-motong asalusulnya. Sementara itu, hati kami remuk karena kelalimannya

Bangsa yang merdeka murni tidak mereka pedulikan, bahkan menjadikan bangsa itu tercerai berai

Mereka memotong janji-janji atas penelaahan hak-hak kami karena hak adalah perkara yang sangat besar

Mereka memotong janji-janji atas negeri dan mereka tidak mau tahu bahwa penduduk negeri itu berteriak-teriak

Pendapat mereka: orang Arab di sekitar adalah pagar yang paling kokoh dan paling kuat dari hukuman'

Yang dimaksud bangsa al-Masih adalah para pemeluk agama Kristen, sedangkan bangsa Ahmad adalah pemeluk agama Islam. Mereka adalah penduduk yang menghuni tanah Palestina dengan pemeluk agama Yahudi yang pada tahun 1947 hanya berjumlah enam persen (Abu Khadra, 1991:22) yang tiba-tiba naik menjadi 24 persen pada tahun 1948 dan semakin banyak di setiap tahunnya.

San Remo yang dimaksud dalam puisi di atas adalah Konferensi San Remo yang memutuskan pembagian wilayah di Palestina untuk orang-orang Arab dan orang Yahudi. Pembagian ini hasilnya 
sudah bisa diduga, yaitu keuntungan bagi pihak Yahudi sebagaimana penjelasan berikut.

Negosiasi dengan Prancis (dengan melibatkan Rusia dalam negosiasi) membahas masalah masa depan Irak dan negara-negara Syam. Akhirnya, mereka setuju pada satu kesepakatan yang dikenal dengan Sykes-Picot Agremeent pada bulan Mei 1916 dengan memberikan sebagian besar wilayah-wilayah Irak timur Jordan dan daerah Haifa di Palestina kepada Inggris. Adapun Lebanon dan Suriah tunduk pada pemmerintahan Prancis. Karena pertimbangan banyak pihak yang menghendaki pendudukan atas wilayah Palestina, maka disepakati untuk meletakkannya di bawah pengawasan internasional (Shaleh, 2002:41-42)

Bait selanjutnya menggambarkan bahwa "mereka", yaitu pihak lain yang berarti Inggris dan Zionis menginjakinjak suatu negeri, yaitu Palestina. Kata menginjak mengandung arti menjejakkan kaki dengan tanpa tatakrama dan mengandung arti merusak seperti pada kalimat mereka menginjak-injak rumput halaman rumah saya. Apalagi ditambah dengan ungkapan "memotong-motong asal-usulnya" yaitu perilaku Zionis yang mengganggap bangsa Palestina itu tidak ada dan tanah Palestina itu tanah kosong. Kelaliman Barat juga menjadikan "bangsa yang merdeka murni tidak mereka pedulikan, bahkan menjadikan bangsa itu tercerai berai, memotong janji-janji atas penelaahan hak-hak, tidak mau tahu bahwa penduduk negeri itu berteriakteriak".

Tipuan Barat juga dapat dilihat pada puisi Al-Abusyiyyu. Adalah seorang penyair bernama Burhanuddin Ibn alHasan Al-Abusyiyyu yang lahir di Jenin pada tahun 1911. Dia pernah mengenyam pendidikan di Universitas Amerika di Beirut meskipun hanya setahun. Hal itu karena ia harus kembali ke Palestina sebab masalah politik. Pada tahun 1941 ia terlibat dalam perang melawan Inggris di barat kota Bagdad. Ia kemudian menulis puisi tentang peristiwa yang terjadi di Palestina yang di antaranya adalah puisi yang ditujukan kepada Weizmann, Presiden Organisasi Zionis dunia pada tahun 1939-1946 dan juga presiden pertama Israel yang menjabat pada tahun 1949-1952. Ia menggambarkan perkataan Weizmann dengan mengatakan:

$$
\begin{aligned}
& \text { أبشـــــركم بالفوز و الفوز يُفرح } \\
& \text { فقد نجح المسعى و ذو الجد ينجح لئحرح } \\
& \text { فلسطين قد أضحى لنا جل أرضها } \\
& \text { و بعد غد تغدو هناك و نســـــرح } \\
& \text { ترعت لكم بالمــــال وعدا مصدقا فلـا } \\
& \text { فتيهوا بهذا الوعـــــــيا قوم وافرحوا }
\end{aligned}
$$

(Syarab, 2006:75)

'Aku memberi kalian kabar gembira dengan kemenangan dan kemenangan itu membahagiakan. Jalannya telah sukses dan orang yang bersungguh-sungguh akan sukses.

Keagungan bumi Palestina telah berkorban untuk kita dan besok kita berada di sana dan bisa datang dan pergi

Engkau akan penuh dengan harta sebagai janji yang benar. Karena itu, berbanggalah dengan janji ini, wahai kaumku dan bergembiralah'

Puisi di atas menggambarkan perkataan Weizmann yang memberikan semangat dan harapan besar kepada anggota Zionis yang akan pindah ke Palestina. Bahkan, seakan-akan tanah Palestina itu telah menanti kehadiran para anggota Zionis. Slogan Zionis "Tanah tak berpenghuni untuk bangsa tak mempunyai tanah" terus menerus didengungkan untuk menyakinkan orang-orang Yahudi agar pindah ke Palestina. Puisi ini sesungguhnya ingin menggambarkan betapa hal yang dikatakan Weizmann itu 
bohong karena Palestina bukanlah tanah yang kosong, tetapi tanah yang berpenghuni dan penghuninya adalah suatu bangsa yang telah tinggal di tanah Palestina ini sejak nenek moyangnya.

\section{Akibat Buruk Deklarasi Balfour}

Deklarasi Balfour telah ditetapkan oleh Inggris dan ketetapan itu memberi jalan yang lapang bagi Zionis untuk mempersiapkan rencana mereka menjadikan Palestina sebagai negara khusus orang Yahudi. Berikut adalah usaha-usaha besar yang dilakukan Zionis.

\subsection{Rencana Inggris tentang Kepindahan Orang-orang Yahudi ke Palestina}

Khalil ibn Qastandi as-Sakakiniy lahir pada tahun 1878 di al-Quds. Dari tahun kelahirannya ia dapat menyaksikan berbagai peristiwa yang terjadi di Palestina. Di antaranya adalah ketika Inggris menyusun rencana penempatan orang-orang Yahudi di Eropa di tanah Palestina, yaitu dengan puisinya berikut.

$$
\begin{aligned}
& \text { نهن قوم أبيـــونا لا نقر الذل فينا } \\
& \text { لا نبالي منايانــــــــ في سبيل أمانينا } \\
& \text { يا بلادا ورثناها عن جدود ميامينا } \\
& \text { إن يهاجمك زوزور يلق منا شواهينا }
\end{aligned}
$$

(Syarab, 2006:143)

'Kami adalah bangsa bernenek moyang yang tak kenal kehinaan

Kami tidak peduli malam-malam kami untuk keamanan

Wahai negeri yang kami warisi dari nenek moyang kami

Bila burung zuzur menyerangmu, ia akan melemparkan kebaikankebaikan kita'

Bangsa Palestina adalah sebuah bangsa yang telah ada sejak nenek moyangnya sehingga dikatakan "negeri yang kami warisis dari nenek moyang kami". Puisi ini juga menyebut kata zuzur, yaitu "burung sejenis yang lebih besar daripada burung pipit, berparuh panjang, berbadan lebar, dan bersayap panjang. Burung ini berasal dari Eropa dan Asia
Utara yang datang ke Palestina ketika zaitun berbunga" (maajim.com). Burung zuzur adalah simbol kedatangan orangorang Yahudi dari wilayah Eropa yang kedatangannya menimbulkan kerusakan seperti burung zuzur yang menyerbu panen buah zaitun. Di samping itu, kedatangan orang-orang Yahudi juga menyebabkan hilangnya lahan-lahan pertanian zaitun yang telah berabad-abad ditanam oleh nenek moyang bangsa Palestina.

\subsection{Pendirian Organisasi Yahudi di Palestina Tahun 1917}

Pada tahun 1917, segera setelah ditandatanganinya Deklarasi Balfour, penyair Palestina, Wadi al-Bustaniy, melihat papan nama bertuliskan "alJam'iyyah al-Yahudiyyah - ar-Ra'is alMulazim Makruriyun" (Organisasi Yahudi - Letnan Kepala Kembali ) di sebuah ruangan di Kantor Pemerintahan. Ia menyambutnya dengan puisi berikut.

$$
\begin{aligned}
& \text { أرى الوطن القومي يعلو بنــــــاؤه } \\
& \text { أرى غرفة في القصر تحجبه قصرا } \\
& \text { و ذكرهم ذكرى و لست مسيطرا }
\end{aligned}
$$

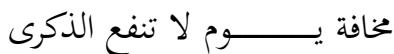

(Yāgī, 1984:20)

'Aku melihat tanah airku meninggi bangunannya, aku melihat sebuah kamar di istana menutupi istana yang lain

Penyebutan mereka adalah peringatan dan aku tak kuasa, aku khawatir suatu hari waktu suatu peringatan tidak bermanfaat lagi'

Setelah Perjanjian Balfour disepakati, organisasi Yahudi segera menunjukkan dirinya secara terangterangan di Palestina, sedangkan bangsa Palestina, termasuk para pemukanya, tidak kuasa melarangnya karena ketidakberdayaan yang telah dibuat oleh Inggris sejak negosiasi yang dilakukannya dengan Syarif Husain, salah seorang anggota parlemen Palestina yang menentang kedatangan orang-orang 
Yahudi, tetapi juga menjual tanah-tanah Palestina ke Yahudi. Al-Bustaniy mengkhawatirkan kejadian ini akan berlanjut pada kejadian-kejadian yang membahayakan posisi Palestina sehingga ia katakan 'suatu hari waktu peringatan tidak bermanfaat lagi'.

\subsection{Peletakan Batu Pertama Pembangunan Universitas Ibrani 1920}

Enam bulan setelah penjajahan Inggris atas al-Quds terjadi, Inggris bersama kelompok Yahudi mengadakan upacara peletakan batu pertama pendirian Universitas Ibrani pada 27 Agustus 1918. Upacara ini dihadiri oleh Mufti al-Quds dari pihak Islam dan pendeta Gereja Anglikan dari pihak Nasrani. Penyair Palestina Wadi al-Bustaniy merasa prihatin atas hal ini sehingga ia menuangkannya dalam bait-bait berikut.

$$
\begin{aligned}
& \text { أفتني بالله بالكعبة بالحجر }
\end{aligned}
$$

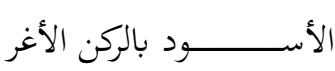

$$
\begin{aligned}
& \text { إن علت في عزها شـامخة } \\
& \text { فوق رأس الطور تلهو بالعبر } \\
& \text { و غدت جامعة عبرية } \\
& \text { وفي الحاخام فيــــــــــا و أمر } \\
& \text { أ يقول الشيخ و القس آنئذ } \\
& \text { إن للمطران و المفتي حجر؟ }
\end{aligned}
$$

(Yāgī, 1984:20; Syarab, 2006:474)

'Demi Allah, demi batu hitam persegi, demi pojok, itu membuatku takut

Jika meninggi dalam

kehormatannya dengan congkak di atas puncak bukit Tur bersenangsenang dengan orang-orang yang bersedih dan bercucuran air matanya

Besok Universitas Ibrani dan pemimpin Yahudi di sana dapat melarang dan memerintah Akankah pemimpin Islam dan Nasrani ketika itu berkata bahwa bagi pendeta dan mufti juga punya batu?'

Deklarasi Balfour memberi kepercayaan diri yang besar pada Zionis untuk membangun universitas yang nantinya untuk menjadi tempat untuk mencetak para ahli Yahudi di berbagai cabang ilmu. Tahun 1920 ini dimulai dengan peletakan batu pertamanya. Penyair mengingatkan bahwa bila nanti universitas itu sudah berdiri, negara Yahudi akan berdiri dengan kuat sehingga dapat "melarang dan memerintah" sesuai dengan kebutuhannya. Ketika itu juga, para pemimpin Palestina, baik Nasrani maupun Islam, sudah tidak didengar lagi pendapatnya.

\subsection{Pendirian Pabrik Minuman Keras Tahun 1920}

Setelah pendirian Universitas Ibrani, Inggris mendirikan pabrik minuman keras di desa bernama Uyuni Qarah, Yafa yang pada saat itu dihadiri oleh Mufti Yafa mendampingi Perwakilan Inggris di al-Quds, Herbert Samuel. Pada saat itu, Mufti mendapat kehormatan menuangkan sekeranjang buah anggur ke dalam alat pemeras anggur (asy-Syarab, 2006:474). Wadī` al-Bustāniy:

$$
\begin{aligned}
& \text { يا مفتي الإسلام تعصر خمرة } \\
& \text { عند اليهود و ما هديت تهودا } \\
& \text { أنكرت دين محمد و محمد } \\
& \text { اليوم تعصرها و تشربها غدا }
\end{aligned}
$$

(Yāgi, 1983:21)

'Wahai mufti Islam, engkau memeras khamr untuk Yahudi, sedangkan engkau bukan Yahudi Hari ini, engkau ingkari agama Islam dan juga Muhammad. Engkau memeras sekarang dan engkau minum besok'

Puisi ini mengemukakan dua hal, yang pertama mengabarkan pendirian pabrik minuman yang dinilai oleh Penyair akan membuat bangsa Palestina terbiasa dengan minuman haram itu dan yang 
kedua adalah krisis kepemimpinan dengan kehadiran Mufti Yafa di acara itu karena seorang mufti yang merupakan pemuka Islam merestui pendirian pabrik minuman keras. Kerjasama Mufti dengan Zionis membuat gusar bangsa Arab yang disuarakan oleh para penyairnya.

\subsection{Peresmian Pembukaan Universitas Ibrani Tahun 1927}

Deklarasi Balfour juga menjadi pijakan bagi Organisasi Zionis untuk mempersiapkan sarana pendidikan mereka, yaitu dengan adanya peresmian Universitas Ibrani. Besarnya peran Deklarasi ini dan dukungan Inggris ditandai dengan hadirnya penggagas deklarasi, yaitu Balfour. Peresmian ini juga dihadiri oleh Ahmad Luṭiy asSayyid, Menteri Luar Negeri Mesir. Kehadiran pihak Mesir memberi kesan bagi bangsa Palestina bahwa Mesir tidak mendukung perjuangan bangsa Palestina padahal bangsa Mesir adalah bangsa Arab sebagaimana bangsa Palestina.

Peristiwa peresmian Univeritas Ibrani dengan kehadiran Balfour dan Lutfiy as-Sayyid di atas ditanggapi oleh Iskandar al-Khuriy al-Baitajaliy dengan puisi berikut.

$$
\begin{aligned}
& \text { الله أكبر كل هذا في سبيل الجامعة ! }
\end{aligned}
$$

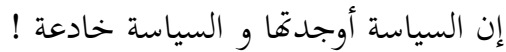

$$
\begin{aligned}
& \text { من لندن هرولت تضرم نار هذي الواقعة ! }
\end{aligned}
$$

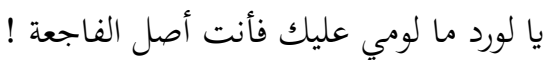

(Yāgī, 1984:23)

'Allah Maha Besar, semua ini untuk sebuah universitas !

Politik yang mewujudkannya dan politik itu menipu !

Dari London Herald dimulai api

kejadian ini !

Wahai Lord, apa salahku padamu.

Dari kamulah asal bencana ini !

Setelah peletakan batu pertama yang terjadi pada tahun 1920 , maka pada tahun 1927 pembangunan universitas telah selesai. Universitas yang dimaksud di sini adalah Universitas Ibrani yang dapat diwujudkan berkat "politik yang menipu". Produk dari tipuan politik ini adalah Deklarasi Balfour karena isinya adalah penyediaan sebuah tanah air khusus Yahudi di tanah yang seolah-olah tidak ada penghuninya. Ungkapan "wahai Lord" ditujukan kepada pengampu kebijakan Inggris yang kala itu adalah Menteri Luar Negeri Inggris, Arthur Balfour, yang dianggap sebagai asal tragedi penjajahan di Palestina.

\subsection{Masjid al-Aqsa dan Yerusalem Dikuasai Inggris Tahun 1935}

Abdurrahim Mahmud Abdurrahim lahir pada tahun 1913 di Tulkarim (Syarab, 2006:238). Ketika Raja Saud ibn Abdul-Aziz mengunjungi Palestina pada tahun 1935, ia menghadangnya sambil membacakan puisinya:

$$
\begin{aligned}
& \text { يا ذا الأمير أمام عينيك شاعر }
\end{aligned}
$$

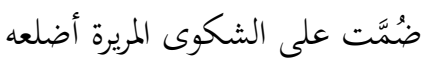

$$
\begin{aligned}
& \text { المسجدُ الأقصى: أجئتُ تزوره }
\end{aligned}
$$

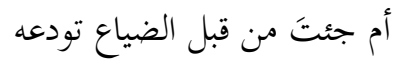

$$
\begin{aligned}
& \text { و غدا و ما أدناه لا يبقى سوى مئ فيل إسياع } \\
& \text { دمع لنا يهمي و خدِّ نقرعه }
\end{aligned}
$$

(Syarab, 2006:240)

'Wahai Raja, di depanmu ada penyair yang dadanya penuh dengan keluhan yang pahit.

Tentang Masjid al-Aqsa: Apakah engkau mengunjunginya atau datang sebelum kehilangannya.

Esok dan esoknya lagi tidak ada yang tersisa kecuali air mata kita yang runtuh dan pipi yang kita pukuli'

Puisi ini disampaikan untuk mengingatkan Raja Saudi, yaitu Ibn Saud yang bertakhta antara tahun 1932 sampai 1953 bahwa kesepakatan yang dilakukannya dengan Inggris itu tidak benar dan merugikan pihak Arab. Penyair menyindir Raja akan kedatangannya di Masjid al-Aqsa itu hanya untuk berkunjung atau untuk mengucapkan 
selamat tinggal sebelum diokupasi oleh Inggris dan Zionis? Kedatangan Raja Saudi ini tidak punya arti apapun bagi bangsa Palestina, bahkan menambah kepedihan karena ketika tanah air mereka telah terjajah ada pemimpin Arab yang dianggap memihak kepada penjajah dan tidak peduli akan nasib bangsa Palestina yang juga bagian dari bangsa Arab.

Puisi penyair Palestina, Harun Hasyim Rasyid, menggambarkan akibat ketetapan Deklarasi Balfour,

$$
\begin{aligned}
& \text { لولا خداع الانكليز و غدرهم } \\
& \text { ما عاث في أرض الأسود كلاب } \\
& \text { و الغرب يا للغرب إن قدومه } \\
& \text { نحو البلاد مصيبه و خراب } \\
& \text { هو اخطبوط فاجر مستعمر } \\
& \text { في كل ناحية له أذناب }
\end{aligned}
$$

(Yāḡi, 1983:81-82)

'Kalau bukan karena tipudaya Inggris, anjing tidak akan hidup di tanah singa

Barat oh Barat, kedatanganmu ke negeri ini adalah musibah dan kehancuran

Ia adalah gurita lacur lagi penjajah yang dari segala penjuru punya sengat penghancur'

Deklarasi Balfour adalah tipu daya Inggris atas Palestina yang menyebabkan penjajah "anjing" hidup di tanah bangsa Arab "singa". Ketetapan Deklarasi Balfour telah menghancurkan eksistensi Palestina dan bangsanya dalam kepingan yang berserak di seluruh dunia dan masih berlangsung hingga saat ini.

\section{Sikap Optimis Bangsa Palestina}

Deklarasi Balfour juga memicu reaksi dari seorang penyair pejuang, yaitu Farhan Salam yang menulis puisi berjudul Marsīatu Falasțina 'Keluhan Palestina':

$$
\text { فلسطين لا تحزي يا زهرة البـلدان }
$$

$$
\begin{aligned}
& \text { خبر ملوكك و الوزراء و الأعيـان }
\end{aligned}
$$

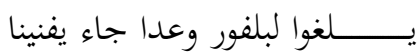

$$
\begin{aligned}
& \text { إن كان بلفور يجهل قيمة الأوطان }
\end{aligned}
$$

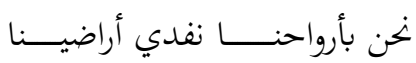

$$
\begin{aligned}
& \text { كم لجنة يا غرب حققت بالأوطان } \\
& \text { تسمع شكاوي الأعادي مع شكاوينا } \\
& \text { تقاريرهم أهملت بأي شرع كــــان } \\
& \text { لولا الدراهــــم واشتيرن و صهيونا } \\
& \text { يا غرب نهن من نسل قــــطان } \\
& \text { تاريـــــنـا يعلمك أحوال ماضينا }
\end{aligned}
$$

(Syarab, 2006:311)

'Wahai Palestina, wahai kembang negeri-negeri, jangan takut. Bumi Arab akan menebusmu bersama khalayaknya

Kabar rajamu, para menteri, dan pembesar, mereka menipu dengan Deklarasi Balfour yang datang menghancurkan kami

Bila Balfour tidak tahu nilai tanah air, kami dengan jiwa kami akan menebus bumi kami

Banyak lembaga, wahai barat, yang mengaktualisasi tanah air yang mendengarkan keluhankeluhan kami

Keputusan-keputusan mereka omong kosong dari hukum apa saja selain uang, tiran, dan yahudi Wahai barat, kami keturunan Qahtan, sejarah kami mengajari masa lalu kami'

Ungkapan "Bumi Arab akan menebusmu bersama khalayaknya" adalah ungkapan optimis bahwa bangsa Palestina bersama bangsa Arab yang lain akan terus berjuang demi kembalinya Palestina. Meskipun telah banyak kesepakatan, keputusan, atau perjanjian yang dilakukan Barat untuk kepentingan Palestina, tetapi kenyataannya selalu berakibat buruk bagi Palestina sehingga dikatakan "omong kosong". Ungkapan bahwa semuanya "omong kosong selain uang, tiran, 
Yahudi" menunjukkan bahwa Palestina benar-benar tidak mendapat keadilan.

Suku Qahtan adalah suku-suku bangsa Arab yang merupakan keturunan Nabi Ibrahim yang mendiami wilayahwilayah Arab mulai dari wilayah Syam sampai Jazirah Arab. Nabi Ibrahim adalah salah seorang Nabi yang tinggal dan dimakamkan di sebuah kota di Palestina yang memakai gelarnya sebagai Kekasih Allah, yaitu al-Khalil atau yang terkenal juga dengan sebutan Hebron. Suku Qahtan disebutkan dalam puisi ini sabagai tanda bahwa bangsa Palestina akan terus berjuang untuk kembali ke tanah airnya karena mereka ingin menegaskan bahwa bangsa Palestina adalah penduduk asli tanah Palestina yang punya alasan kuat untuk tetap memiliki bumi dan tanah airnya.

Inggris melalui Menteri Luar Negerinya, Boris Johnson, mengatakan bahwa ia bangga dengan peran Inggris dalam membantu berdirinya negara Israel dan ia mengatakan bahwa dokumen Balfour itu memiliki nilai moral yang tak terbayangkan. Penting untuk memberi orang-orang teraniaya tempat yang aman dan nyaman (Haaretz, 30/10/2017). Pernyataan itu wajar apabila dipandang dari pihak Inggris sebagai penjajah, penggagas sekaligus pelaksana Deklarasi Balfour. Akan tetapi, Inggris tidak melihat sisi lain yang diakibatkan oleh dukungannya, yaitu kehancuran bangsa Palestina.

\section{Simpulan}

Deklarasi Balfour yang dicanangkan pada tahun 1917 telah berhasil dengan gemilang menciptakan negara khusus bagi Yahudi, yaitu negara Israel dan di waktu yang bersamaan juga telah berhasil memusnahkan suatu bangsa, yaitu bangsa Palestina. Inggris bersama Amerika telah menyebabkan hilangnya hak bangsa Palestina atas buminya, yaitu bumi Palestina.

Bangsa Palestina adalah bangsa yang teguh dalam berjuang. Hal itu terbukti dengan perjuangan yang mereka lakukan sejak Palestina dijajah Israel hingga saat ini. Bangsa Palestina belum mencapai tujuan perjuangannya hingga saat ini meskipun banyak negara telah mendukung kemerdekaannya melalui organisasi dunia, Persatuan Bangsabangsa (PBB). Meskipun demikian, daya juang itu tidak pernah surut meskipun telah terjadi pergantian generasi dalam penjajahan yang telah berlangsung hampir satu abad.

Para sastrawan Arab, khususnya para penyair, mempunyai peran yang besar dalam perjuangan Palestina karena karya mereka terus menginspirasi bangsa Palestina dari generasi ke generasi dalam berjuang melawan penjajah. Para penyair menyertai perjuangan bangsa Palestina, baik mereka yang berada di tanah Palestina maupun yang tersebar di seluruh dunia. Peringatan demi peringatan yang disampaikan para penyair pada akhirnya sungguh-sungguh terjadi akibat kelalaian para pemuka Palestina.

November tahun 2017 adalah seratus tahun Deklarasi Balfour diumumkan dan isinya dilaksanakan. Inggris telah berhasil membuat tanah Palestina terjajah dan bangsa Palestina terusir. Inggris merasa bangga hingga saat ini bahwa Inggris telah berhasil memberikan sebuah negara bagi Israel. Sebuah kebanggaaan yang dijejakkan di atas keporakporandaan bangsa Palestina.

\section{Daftar Pustaka}

Abī Khaḍrā, Faișal. 1991. TārīkhulMas 'alatil-Falasținiyyati alAzmati wal-Halli. Qalyubi: Matabi il-Ahram at-Tijariyyah.

Al-Ayyūbiy, Yasin. Tanpa Tahun. "Adabul-Muqāwamah" dalam Al-Mautu wal-Hayātu fi Syi 'rilMuqāwamah. Beirut: DarurRa'idil-'Arabiy.

Bazian, Hatim. Tanpa tahun. The Balfor Declaration: $\quad$ Palestine's Colonial Legacy. Diunduh dari 
https://www.academia.edu/9069 377/ The Balfor Declaration: Palestine's Colonial Legacy.

Dimont, Max I. 1993. Desain Yahudi atau Kehendak Tuhan : Narasinarasi Besar Bagi Sebuah Sejarah Dunia diterjemahkan dari Jews, God, and History. Bandung : Eraseni Media.

Goldschmidt Jr. Arthur dan Lawrence Davidson. 2010. A Consise History of The Middle East. Philadelphia:Westview Press.

Haaretz. 2017. 'U.K.'s Boris Johnson Defends Balfour Declaration: 'Proud of Britain's Part in Creating Israel" in Haaretz https://www.haaretz.com 30.10.2017

Haddād, Yūsuf Ayyūb. 1982. Falasțīnu fi al-Adabi al-Mahjariyyi. Muassasah Fikrul Abhas.

Hiro, Dilip. 1996. The Middle East. Oryx Press.

al-Husain, Qușay. Tanpa Tahun. AlMautu wal-Hayātu fi Syi'rilMuqāwamah. Beirut: DarurRa'idil-Arabiy.

Al-Husainiy, Suhailah. 2006. Qirā'atun fi Adabil-Muqāwamah fil-WatanilArabiy. Al-Qahirah: MaktabatulAdab.

Kanafāniy, Gassān. 1968. Al-Adabu alFalastīniyyu al-Muqāwimu Tahta al-Ihtilāli 1948-1968. Cetakan Pertama. Beirut: Mu`assasatu ad-Dirāsāti alFalasținniyyati.

Khān, Zafaru al-Islam. 1992. Tārīkh Falastīn al-Qadīm Munżu Awwali Gazwin Yahudiyyin Hatta Akhiri Harbin Salibiyyin. Beirut: Daru an-Nafa isi.
Munawwir, Ahmad Warson. 1997. AlMunawwir: Qamus ArabiyyunIndunisiyyun. Yogyakarta: Unit Pangadaan Buku Ilmiah Kegamaan Pondok Pesantren Krapyak.

Natsir, M. 1970. Masalah Palestina. Jakarta: Penerbit Hudaya bekerjasama dengan Yayasan Dewan Da`wah Islamiyah Indonesia.

An-Naqqasy, Raja`. 1971. Mahmūd Darwīsy Syāiru Ardi alMuhtallati. Dar al-Hilal.

Parkes, James W. 2002. Sejarah Palestina. Diterjemahkan dari judul asli The History of Palestine. Yogyakarta: Penerbit Sketsa.

Al-Usțah, 'Ādil. Tanpa Tahun. Istiqbālu Syi'ri al-Muqāwamati fi anNaqdi al-Adabiyyi fi al-'̄lami al-'Arabiyyi.

Shaleh, Muhsin Muhammad. 2001. Palestina : Sejarah, Perkembangan, dan Konspirasi. Diterjemahkan dari judul The Palestinian Issue: Its Background and Development Up to 2000. Cetakan ke-1. Jakarta :Gema Insani.

Syarîf, Husain. 2003. Falastinu min Fajri at-Tarikhi ilā Intifadati al-Aqsa wa Tawābi'iha Hatta 2002 M. al-Hai`atu al-Mișriyyatu li alAmmatu li al-Kitabi.

Syarāb, Muhammad Muhammad Hasan. 2006. Syu'ara'u Falasțin fil'Ascril-Hadīs 'Para Penyair Palestina Masa Modern'. Cetakan ke-1. 'Amman: alAhliyyah.

Tucker, Spencer C (ed). 2008. The Encyclopedia of the Arab-Israeli Conflict: A Political, Social, and 
Military History. Santa Barbara California: ABC-CLIO Ltd.

Yāgī, Abdurrahmān. 1983. Fil-Adabil-

Filastiniyyil-Hadīs. al-Kuwait:

Syirkah Kazimah lin-nasyri wat-

Tauzi`wat-Tarjamah. 